\title{
CRISE E ESCASSEZ: A CRISE FINANCEIRA DO ESTADO DO RIO GRANDE DO SUL E SUAS IMPLICAÇÕES NAS POLÍTICAS PÚBLICAS
}

\author{
Janaína Rigo Santin*1 \\ Jander Rocha da Silva**2
}

RESUMO: A temática das finanças públicas no Brasil vem tomando conta do cenário político e econômico nos últimos anos. Em se tratando da realidade do Estado do Rio Grande do Sul, o problema vem impondo severos desafios aos gestores públicos que passam pelo Palácio Piratini, pauta das principais discussões locais desde meados da década de 70 e que se agudizou com a pandemia da Covid-19, impedindo toda e qualquer agenda de desenvolvimento para o Estado. O objetivo do artigo é fazer uma análise da perspectiva histórica desta crise, avaliando as suas consequências para as políticas públicas sulriograndenses.

PALAVRAS-CHAVE: Administração Pública; Finanças Públicas; Estado do Rio Grande do Sul; Direitos Sociais; Políticas Públicas.

\section{CRISIS AND SCARCITY: RIO GRANDE DO SUL'S FINANCIAL CRISIS AND IMPLICATIONS IN THE PUBLIC POLICIES}

\begin{abstract}
The theme of public finances in Brazil has been taking over the political and economic scenario in recent years. In the Rio Grande do Sul state, the problem has been imposing severe challenges on public managers who pass through the Piratini Palace, which has been the focus of the main local discussions since the mid-1970s and which has been aggravated by the Covid-19 pandemic, impeding any and all development agenda for the State. The objective of the article is to analyze the historical perspective of this crisis, assessing its consequences for public policies in Rio Grande do Sul.
\end{abstract}

KEYWORDS: Public Administration. Public Finance. Rio Grande do Sul State. Social Right; Public Policies.

\section{INTRODUÇÃO}

A temática de crise das finanças públicas no Brasil é um tema que vem tomando conta do cenário político e econômico nos últimos anos, agravada ainda mais a partir de

\footnotetext{
${ }^{1}$ Pós Doutora em Direito Administrativo pela Universidade de Lisboa, Portugal, com apoio CAPES. Doutora em Direito pela Universidade Federal do Paraná. Mestre em Direito pela Universidade Federal de Santa Catarina. Advogada e Professora Titular II da Universidade de Passo Fundo. Docente permanente do Programa de Mestrado e Doutorado em História da Universidade de Passo Fundo/RS. Professora colaboradora do Mestrado em Ciências Jurídicas-Econômicas e Desenvolvimento e do Mestrado em Governação e Gestão Pública da Universidade Agostinho Neto, em Luanda, Angola-África. Colaboradora do PPGD/UCS. Endereço eletrônico: janainars@upf.br

${ }_{2}^{2}$ Mestrando em Direito pelo Programa de Pós-graduação em Direito da Universidade de Passo Fundo. Pósgraduando em Direito Administrativo e Gestão Pública pela Fundação Escola Superior do Ministério Público: 154594@upf.br
} 
2020, com a pandemia da Covid-19. Esta situação de crise recorrente traz consequências diretas no fluxo depagamentos e na elaboração e execução das políticas públicas, sobretudo na incansável tarefa de busca pela efetivação dos Direitos Fundamentais Sociais, definidos no artigo $6^{\circ}$ da Constituição Federal de 1988.

Em especial após 2014, o Brasil mergulhou em uma das mais profundas crises econômicas de sua história, o que trouxe consequências devastadoras para o setor Público, como o aumento do endividamento e a queda de receitas em decorrência da recessão econômica, a qual foi agravada com a pandemia. ${ }^{1}$ Dentre os entes federativos mais afetados estão os Estados-membros, que viram suas receitas em "queda livre" e seu gasto aumentar de forma vertiginosa, chegando até mesmo a estourar os mecanismos de controle impostos pela Lei de Responsabilidade Fiscal (Lei Complementar 101 de 2000) entre os anos de 2015 e 2016, no tocante ao gasto com pessoal. Alguns deles precisaram decretar estado de calamidade financeira sobre a Administração Pública, devido à situação de quase insolvência.

Dentre os Estados da federação mais prejudicados encontra-se o Rio Grande do Sul, cuja crise vem permeando as discussões no campo econômico, fiscal e político desde meados da década de 70. O grave quadro de sua dívida foi ocasionado por mais de 40 anos de sucessivosdéficits orçamentários, situação agravada com o Plano Real, o que levou o estado a renegociar com a União a sua dívida pública em 1998. Neste acordo, o estado comprometeu-se a uma responsabilidade fiscal, o que não foi atendido. Pelo contrário, nos anos subsequentes houve um aumento expressivo dos gastos públicos estaduais, em especial com inativos, o que levou o estado a uma permanente crise estrutural, fruto de um descompasso de décadas entre a receita e a despesa pública. (MARQUES JÚNIOR, 2015)

\footnotetext{
${ }^{1}$ Nas palavras de Fernando de Holanda Barbosa Filho, a "economia brasileira encontra-se formalmente em recessão desde o segundo trimestre de 2014, segundo o Comitê de Datação do Ciclo Econômico (Codace) da Fundação Getulio Vargas. O produto per capita brasileiro caiu cerca de $9 \%$ entre 2014 e 2016.” Para o autor, a origem da crise econômica de 2014/2017 se deu a partir de "uma série de choques de oferta e demanda, na maior parte ocasionados por erros de políticas públicas que reduziram a capacidade de crescimento da economia brasileira e geraram um custo fiscal elevado. A taxa de crescimento do produto potencial da economia brasileira saiu da faixa de $4 \%$ ao ano para menos de $2 \%$ ao ano. Ao mesmo tempo, o setor público brasileiro abandona um superávit primário de 2,2\% em 2012 e gera um déficit primário de 2,7\% em 2016. [...] A crise de sustentabilidadefiscal que se seguiu elevou o risco país, a taxa de juros de longo prazo e a incerteza, reduzindo consumo e investimento de forma substancial em 2015 e 2016. A recomposição de preços e a política monetária necessária para recolocar a inflação na meta também contribuem para a recessão, principalmente devido à perda de credibilidade do Banco Central.” (2017, p. 51-58)
} 
O objetivo do presente trabalho é fazer uma análise da evolução desta crise até o panorama dos dias atuais, perpassando os diversos governos e suas medidas para o enfrentamento da permanente crise estrutural do Estado. E, por fim, tenciona-se discutir as severas implicações que um setor público completamente desregrado possui para a execução das políticas públicas e para o desenvolvimento econômico e social em âmbito do poder local estadual.

\section{O AUMENTO DO ENDIVIDAMENTO EM ÂMBITO NACIONAL E A CRISE}

Ao longo da história, as crises econômicas acabaram fazendo parte do dia a dia dos governos, o que acaba por afetar de forma direta a vida das pessoas em suas mais diversas dimensões, com reflexos no poder de compra dos salários, na diminuição do consumo, dentre outros. Todavia, uma crise dificilmente se dá maneira isolada, podendo haver crises internas, decorrentes de problemas nacionais, ou crises externas, por conta do cenário internacional; porém, todas elas afetam, de uma maneira ou de outra, as economias nacionais. No entanto, a complexidade do cenário aumenta "quando crises bancárias evoluem para crises governamentais ou da dívida pública, em que as dívidas das instituições financeiras falidas acabam sendo assumidas pelos próprios governos" (DAMAS, 2017, p.13).

Nessa esteira, são inúmeras variáveis que "podem suscitar o estouro de uma bolha especulativa precedida de um ataque contra a moeda de um país" (DAMAS, 2017, p.17). Destaca-se alguns denominadores comuns para o prenúncio de uma crise, "como a percepções crescentes de indícios de risco traduzidas em excessivos déficits do balanço de pagamentos” e as fragilidades dos "sistemas financeiros desregulamentados, que fazem que uma crise cambial ou do balanço de pagamentos se transforme em uma crise econômica com drásticos efeitos para a economia real do país". No entanto, "a crescente globalização financeira, o aumento do fluxo de capitais entre as nações, e o risco embutido nessas movimentações" tornaram-se indicadores "extremamente relevantes para a utilização de diversos instrumentos que permitam identificar ou antecipar qualquer fragilidade externa e econômica de um país” (DAMAS, 2017, p.17).

$\mathrm{Na}$ visão de Jonathan Bernstein, define-se crise como "qualquer situação que ameaça ou pode ameaçar a integridade de pessoas ou propriedades, e seriamente interromper um negócio, arranhar reputações ou impactar negativamente o valor de mercado" (apud FORNI, 2019, p. 06). Já Ian Mitroff possui um conceito mais direto, definindo uma crise como "um evento que afeta ou tem o potencial de afetar uma organização inteira", algo negativo que não 
se pode conter "dentro das paredes de uma organização". Porém, o autor admite que, "apesar de nem todas as crises serem previstas, todas podem ser administradas nos limites do humanamente possível" (apud FORNI, 2019, p.06).

A crise pode ser considerada como uma ruptura com o estado de normalidade, o que gera emergências, onde há a necessidade de uma rápida intervenção por meio de um plano estratégico. Em se tratando de uma crise econômica, este período é definido como um tempo em que a economia passa por uma retração, que é medido por meio do decréscimo na curva do PIB (produto interno bruto) do país. Isso traz, como consequência, a piora nos indicadores econômicos como a retração do consumo, o aumento do desemprego, a baixa nos investimentos, dentre outros. Já as consequências das crises para o setor público podem ser medidas a partir da queda acentuada da arrecadação de tributos e na piora dos indicadores fiscais. Com este, cenário, é possível dizer que nos últimos anos o Brasil passou por inúmeras crises econômicas, sendo as mais recentes nos anos de 2015 e 2016, o que foi gravemente acentuado em 2020 pela pandemia da Covid-19. Tais fatores exigiram grandes aportes financeiros nos setores da saúde e da economia, atingindo União, os Estados-membros, o Distrito Federal e os Municípios, o que contribuiu para o agravamento ainda maior da crise no setor público brasileiro. (SANTIN; BITENCOURT, 2015)

Passa-se, a partir de agora, a fazer um recorte e analisar exclusivamente a questão da crise financeira do Estado do Rio Grande do Sul.

\section{A EVOLUÇÃO DA CRISE FINANCEIRA DO ESTADO DO RIO GRANDE DO SUL}

No tocante à perspectiva histórica, a crise das finanças do Estado do Rio Grande do Sul teve sua noção embrionária na década de 1940, quando o Estado começou a contrair seus primeiros empréstimos. Já nas décadas seguintes, de 1950 e 1960, os sucessivos governos como o do então Governador Ernesto Dornelles (1951-1955) e do Governador Leonel Brizola (19591963) contraíram novos empréstimos com organismos internacionais, com vistas a viabilizar ambiciosos planos de infraestrutura, como a construção de estradas e escolas. Tratava-se de um período em que a sociedade necessitava da intervenção do Poder Público, sobretudo no interior, adotando-se uma economia de matriz desenvolvimentista para projetar o avanço econômico das diferentes regiões do país. Neste período, a dívida do Estado do Rio Grande do Sul frente aos seus credores já era maior que muitos outros Estados da federação brasileira. No entanto, a dívida estava em patamares sustentáveis com as receitas públicas da época, pois os valores das 
operações de crédito ainda não haviam sofrido correções, pesando pouco sobre os pagamentos do Estado (BUBLITZ, 2016).

Adentrando na década de 1970, houve uma expansão do projeto desenvolvimentista no país. O desequilíbrio entre receitas e despesas foi intensificado com o chamado "milagre econômico brasileiro" oriundo do regime militar, em que o Governo Federal estimulou os Estados a contraírem empréstimos externos para grandes obras de infraestrutura, ocasionando assim um aumento significativo do endividamento estadual. Neste mesmo período, com o aval do então Ministro da Fazenda, Delfim Netto, o então Governador do Rio Grande do Sul Euclides Triches (1971-1975), em dezembro de 1972, "sancionou uma lei para poder emitir títulos com correção monetária, conhecidos como Letras do Tesouro (LTEs) e Obrigações Reajustáveis (ORTES)” (BUBLITZ, 2016). Tais mecanismos de emissão de papéis foram considerados atrativos tanto pelo setor público, que a partir deles obtinha dinheiro para fazer frente aos seus gastos, quanto pelos investidores privados. Houve uma rápida aceitação por parte do mercado destes títulos, o que fez com que governo estadual conseguisse viabilizar a expansão do projeto de desenvolvimento e, por meio deles, se financiar (BUBLITZ, 2016).

Foi neste período que "a Dívida Mobiliária dos estados originou-se de sucessivos déficits fiscais ocorridos entre as décadas de 1970 até meados dos anos 1990" (SILVA, 2014, p.05). Sendo assim, a "existência de déficits primários determinou que os administradores buscassem recursos em outras fontes para reduzir os déficits orçamentários" (SILVA, 2014, p.05). Ou seja, os sucessivos financiamentos contraídos pela venda dos títulos serviram quase que exclusivamente para financiar o déficit público do Estado do Rio Grande do Sul, onde "para substituir os papéis vencidos, novos títulos passaram a ser emitidos, sempre com juros mais altos" (BUBLITZ, 2016).

Já entre a metade e o final da década de 1970, a crise mundial do petróleo atingiu também o Brasil e, por sua vez, o Estado do Rio Grande do Sul. O panorama era de juros nas alturas, receitas próprias despencando e as despesas crescendo, chegando a um crescimento da dívida externa estadual no percentual de $1.736 \%$ (BUBLITZ, 2016). Nas conclusões de Liderau dos Santos Marques Júnior (2015),

A crise das finanças públicas gaúchas pode ser explicada por três componentes. O
primeiro é de longo prazo, representado pela dívida acumulada ao longo de décadas.
O segundo é de médio prazo, caracterizado pela deterioração fiscal ocorrida nos
últimos anos. O terceiro componente é de curto prazo, dado pela recessão econômica
que afeta negativamente a arrecadação tributária estadual. [...] Portanto, somando-se
os três componentes, tem-se instalado o quadro de crise financeira cujos sintomas são
os seguintes. Primeiro, o Governo Estadual administra o caixa no dia a dia e financia- 
se com atrasos junto aos servidores, fornecedores e credores. O efeito do bloqueio das contas do Estado por parte da União é o de elevar ainda mais o nível de financiamento via postergação de despesas. Segundo, as contas públicas não fecham em virtude do excesso de compromissos assumidos no passado e porque a arrecadação está em queda em termos reais. Terceiro e último, esgotaram-se as fontes de financiamento. Isto é, o estoque de depósitos judiciais foi praticamente exaurido, e o limite de endividamento legal foi superado no primeiro quadrimestre de 2015, lembrando-se que, desde 1998, o Estado não pode emitir títulos públicos.

Assim, a década de 1980, tida por muitos economistas como "década perdida" em matéria econômica para o Brasil, trouxe um aprofundamento ainda maior da crise financeira do Estado do Rio Grande do Sul, marcada pela hiperinflação e pela explosão do endividamento público. Nesse período, “os títulos lançados nos anos de 1970 começaram a expirar, e o Estado já não podia resgatá-los" (BUBLITZ, 2016). Tal cenário provocou a falta de recursos para o pagamento de despesas básicas do Estado, como a folha de pagamento dos servidores públicos estaduais. (BUBLITZ, 2016).

Em março de 1983, o então Governador Jair Soares (1983 -1987) assume o Palácio Piratini com um quadro completamente delicado das finanças públicas estaduais, tendo em vista que em maio do mesmo ano corria-se um sério risco de não conseguir pagar os servidores públicos estaduais. A piora nas condições de vida e de trabalho dos professores estaduais ensejou importantes mobilizações, greves, lutas e manifestos da categoria dos professores e o governo do estado. O uso das "sinetas" como símbolo de luta dos educadores gaúchos surgiu na greve de 1985 e se tornou característico dos manifestos e embates na área da educação a partir daí. (MARQUES, 2017) Para se evitar o colapso o governo atendeu às reivindicações. Porém, o endividamento, que já alçava o patamar de $21 \%$ da renda interna estadual, nos anos de 1984 e 1985 passou para 48\% (GUIMARÃES, p. 124, 2007). Diante deste complexo cenário, realizavam-se "operações de crédito por antecipação da receita repetidas vezes. Isto é, recorreu ao mercado para adiantar o que ainda estava por arrecadar, pagando juros e correção" (BUBLITZ, 2016).

Já em 1986, com a introdução do Plano Cruzado e a conversão da moeda de cruzeiro para cruzado, o orçamento público do Estado do Rio Grande do Sul caiu pela metade, aprofundando ainda mais uma crise que já era tida como gravíssima. Neste mesmo ano, é eleito Pedro Simon para comandar o Estado, tomando posse em 15 de março de 1987 com uma situação fiscal em profunda deterioração. Seus primeiros atos foram suspender o pagamento da folha e rever algumas decisões tomadas pelo seu antecessor, atingindo o salário do magistério gaúcho. Tal decisão desencadeou a maior greve do magistério do Estado do Rio Grande do Sul, 
novamente com "sinetaço" e agora também acampamento em frente do Palácio Piratini, somando em 1986 cerca de 96 dias de paralisação. (MARQUES, 2017)

Ressalta-se que, além do avançado quadro de deterioração fiscal do Rio Grande do Sul, outros Estados também se encontravam nesta mesma situação neste período, o que levou a União a editar medidas de auxílio financeiro aos Estados, como o refinanciamento de parte dos empréstimos bancários à conta e risco do Tesouro Nacional. Editou-se a Lei $n^{\circ}$ 7.614, de julho de 1987, "com intuito de atender ao refinanciamento de principal, encargos e moratórios das dívidas vincendas ao final daquele ano e para suprir recursos visando ao financiamento total ou parcial do déficit relativo a despesas correntes de exercícios anteriores até 1987” (SILVA, 2014, p.06).

Não resolvida a situação, no ano de 1989, a União novamente refinancia dívidas de responsabilidade dos entes federativos locais, só que agora para atender à dívida externa. Dessa forma, "por intermédio da Lei $\mathrm{n}^{0} 7.976$ de 1989, a União estabelece o refinanciamento de dívidas, com a finalidade de que sejam honrados os compromissos financeiros decorrentes de operações de crédito externo contratadas pelos governos subnacionais e locais, que eram garantidos pela União" (SILVA, 2014, p. 06).

Porém, todas estas medidas não resolveram o grave problema de endividamento do Estado. Na década de 1990 a crise sobre as finanças públicas continuou se aprofundando, e em março de 1991, quando o então Governador Alceu Collares assume o Governo do Rio Grande do Sul, a situação chega a tal ponto que os títulos emitidos pelo Estado precisavam ser "rolados" diariamente, sendo "necessário oferecer prêmios de risco para que os investidores continuassem financiando o rombo" estadual (BUBLITZ, 2016).

Com o advento do Plano Real em 1994 os problemas dos estados brasileiros ganharam uma dimensão ainda maior. Com o controle inflacionário e a estabilização monetária do Brasil, a inflação, principal fonte de receitas dos governos estaduais, foi contida, o que acabou por aumentar de forma vertiginosa o passivo da dívida estadual, que duplicou em função da alta taxa dos juros. É válido enfatizar que esta problemática não foi apenas um caso exclusivo do Estado do Rio Grande do Sul, já que todos os estados brasileiros que se utilizavam do artifício inflacionário para aumentar as receitas públicas e mascarar seus orçamentos deficitários.

Com isso, Luciana Mattedi e Silva aduz que:

[...] Com a elevação da taxa de juros e o controle inflacionário, os estados passaram a enfrentar dois problemas centrais: o custo da dívida mobiliária torna-se insustentável, obrigando os entes a emitir novos títulos, rolando, assim, os encargos vincendos. 
Segundo, não há mais ganho com o float inflacionário, e as receitas não crescem satisfatoriamente para fazer frente às despesas, principalmente aquelas decorrentes de aumentos concedidos nos anos precedentes ao plano Real, quando ainda havia expectativa de perpetuação da inflação, o que acaba por afetar sobremaneira os resultados primários dos estados (SILVA, 2014, p.08-09).

Em 01 de janeiro do ano de 1995, toma posse o Governador Antônio Britto (19951998) que teve mais uma vez como tarefa desafiadora, sanear as finanças públicas do Estado e abrir diálogo com o Governo Federal para uma nova tentativa de renegociação. Também fez uso de outras fontes de receita, a partir de privatizações. Alienou as duas grandes empresas estaduais, a CEEE (Caixa Econômica Estadual) e a CRT (Companhia Riograndense de Telecomunicações). (GUIMARÃES, 2007, p. 126)

Neste mesmo ano é editada a Resolução no 162/1995 do Conselho Monetário Nacional, que estabelece "um marco no relacionamento entre as esferas de governo, porque, pela primeira vez, associou o auxílio financeiro federal à reforma do setor público estadual e ao ajuste patrimonial" (SILVA, 2014, p.09). Sendo assim, "com base nas premissas estabelecidas pela Resolução no 162/1995 do Conselho Monetário Nacional - CMN, foi promulgada a Lei $n^{\circ}$ 9.496, de 11 de setembro de 1997” (SILVA, 2014, p.09), instituindo o chamado Programa de Apoio à Reestruturação e ao Ajuste Fiscal dos Estados.

O objetivo do presente programa tinha como meta promover "o equilíbrio orçamentário nas unidades da federação, bem como implementar ações que promovessem o equacionamento da insuficiência de recursos" (SILVA, 2014, p.09). Assim, os Estados participantes, além de obterem linhas de financiamento de suas dívidas junto à Caixa Econômica Federal, teriam a obrigação de "fixar, de forma organizada e monitorada, compromissos com metas, ajuste fiscal e saneamento financeiro, sendo forçados a adotar medidas de controle de gastos com pessoal, alienação de ativos (privatização), concessão de serviços públicos e obterem a aprovação à implementação do programa" (ASSEMBLEIA LEGISLATIVA DO RIO GRANDE DO SUL, 2012).

Após dois anos de negociação, o acordo entre o Estado do Rio Grande do Sul e a União se deu em $1998^{2}$, onde a "União assumiu praticamente toda a dívida. O Estado ficou obrigado a pagar R \$ 7,9 bilhões em 30 anos, com juros anuais de 6\% e correção pelo IGP-DI. Os repasses ficaram limitados a 13\% da receita corrente líquida (RCL) "3 (BUBLITZ, 2016). Todavia, apesar da federalização das dívidas dos Estados, o indexador proposto no acordo, o IGP-DI acrescido de uma taxa de juros de $6 \%$ ao ano e a prestação calculada pela tabela PRICE ocasionou uma elevação significativa da dívida ao longo dos anos subsequentes, agravada pela 
desvalorização do real e a adoção de um sistema de câmbio flutuante. (ASSEMBLEIA LEGISLATIVA DO RIO GRANDE DO SUL, 2012)

\footnotetext{
${ }^{2}$ Em 1998, o Rio Grande do Sul realizou a negociação da dívida Estadual dentro do contexto mais amplo do programa de ajuste Fiscal, do qual participou quase a totalidade das unidades da federação, tendo como principal instrumento de renegociação a Lei n ${ }^{\circ}$ 9.496/97 que permitiu trocar a dívida mobiliaria (de curto prazo) em dívida contratual (de longo prazo 30 anos). A renegociação da dívida estabeleceu metas a serem cumpridas pelos Estados. (ASSEMBLEIA LEGISLATIVA DO RIO GRANDE DO SUL, 2012)

${ }^{3}$ Receita corrente líquida é o somatório das receitas tributárias de um Governo, referentes a contribuições, patrimoniais, industriais, agropecuárias e de serviços, deduzidos os valores das transferências constitucionais (CÂMARA DOS DEPUTADOS, 2004).
}

Por sua vez, no período do Governo Olívio Dutra (1999-2002), sem os recursos gerados pelas altas taxas de inflação e sem a venda de empresas públicas, a crise das finanças públicas foi parcialmente contornada fazendo uso do "Caixa Único", de investimentos. Em piores condições, o Governo Germano Rigotto (2003-2006), para fazer face à crise, novamente valeu-se da alternativa de diminuir a capacidade de investimento do Estado para tentar adequar as receitas e as despesas públicas. Porém, o que se percebe é que de 2000 a 2007, a crise não diminuiu, mesmo com a negociação da dívida com o governo federal em 1998 e as inúmeras tentativas de equacionar as contas públicas do Estado pelos governantes, "pois o comprometimento da receita corrente líquida com o serviço da dívida ficou muito alto, reduzindo os investimentos". (GUIMARÃES, 2007, p. 123)

Destaca-se também a política do "Déficit Zero" implementado no Governo Yeda Crusius (2007-2010). Tratava-se de um robusto plano de austeridade fiscal, reestruturação de parte dos gastos, capitalização do Banrisul (banco estatal gaúcho) e empréstimo junto ao Banco Mundial, o que acabou por registrar neste período um superávit nas contas do Estado do Rio Grande do Sul. Apesar disso, o "déficit zero" foi alvo de duras críticas da oposição e "em 2010, no último ano da gestão tucana, o Estado voltou a entrar no vermelho. E não saiu mais". Tarso Genro, governador que a sucedeu, destituiu a política do "déficit zero" e aprovou uma série de reajustes para os servidores públicos. Neste cenário, medidas extraordinárias precisaram ser tomadas com vistas a fazer frente às despesas do Estado, como a autorização para saques do Caixa Único ${ }^{5}$ e a utilização dos Depósitos Judiciais (conta vinculada ao Poder Judiciário Gaúcho), o que também acabou gerando questionamentos por parte da oposição (GAÚCHA $\mathrm{ZH}, 2016)$.

Com o socorro Federal proveniente da promulgação da Lei Complementar no 148 de 25 de novembro de 2014, alterou-se o indexador de atualização monetária, passando do IGP- 
DI para o IPCA (limitado pela taxa Selic) e reduzindo o juro da dívida (de 6\% para 4\%), retroativo a janeiro de 2013. Porém, o endividamento só crescia, e a crise financeira do Estado se aprofundou ainda mais com o expressivo aumento dos gastos públicos promovidos entre

\footnotetext{
${ }^{4}$ Trata-se de uma prática contábil utilizada pela maioria dos estados brasileiros, e inclusive pelo governo federal, para conferir maior fluidez às necessidades de utilização de recursos para pagamento de despesas públicas (STEPHANES, 2013)

5 "Criado em 1991, o chamado Caixa Único (SIAC) reúne atualmente 418 contas correntes, incluindo as dos Poderes e Órgãos Autônomos, demais órgãos de Estado, autarquias, empresas públicas, e aquelas destinadas a receber recursos de convênios e fundos do Poder Executivo. Nos últimos vinte anos, diferentes governos utilizaram recursos depositados nessas contas para quitar despesas que deveriam ter sido quitadas com recursos livres do Tesouro. Em outras palavras, para financiar seus déficits, realizaram saques no Caixa Único acumulando uma dívida com o Caixa Único que, em dezembro de 2018, somava $\mathrm{R} \$ 8,26$ bilhões (excluídos os depósitos judiciais)". (GOVERNO DO ESTADO DO RIO GRANDE DO SUL, 2020, p. 44)
}

2011 e 2014, bem como a crise econômica de 2015 e 2016, que provocou uma recessão econômica e uma consequente queda na arrecadação tributária do Estado. O então governador José Ivo Sartori recebeu o Estado em 2015 em uma situação financeira crítica e adotou medidas de ajuste para reduzir o rombo nas contas públicas. Sem dinheiro suficiente em caixa, passou a parcelar salários de servidores do Poder Executivo e a atrasar pagamentos a fornecedores, repasses a municípios e as parcelas da dívida. Isso fez com que as contas passassem as ser bloqueadas mês a mês, para o sequestro dos valores devidos à União. (GAÚCHA ZH, 2016)

\begin{abstract}
Em dezembro daquele ano, um decreto federal regulamentou a lei ${ }^{\circ} 148$ e estabeleceu os critérios do cálculo retroativo que reduziria a dívida dos Estados (por conta da mudança no índice de correção e nos juros), mas Santa Catarina, Rio Grande do Sul e Minas Gerais discordaram do cálculo, recorreram ao STF e obtiveram liminar favorável. Com isso, o pagamento foi suspenso por 60 dias, e a Corte determinou que os Estados e a União chegassem a um acordo. $\mathrm{O}$ acordo foi anunciado em junho de 2016, depois de longa discussão entre os governadores e o então presidente Michel Temer. (GAÚCHA ZH, 2016)
\end{abstract}

Nesse ponto, tamanhas foram as dificuldades enfrentadas pelo Estado do Rio Grande do Sul, que em novembro de 2016 o Governo lança mão do Decreto $n^{\circ} 53.303$ de 21 de novembro de 2016 que decreta "estado de calamidade financeira" sobre a administração pública estadual, permitindo assim a adoção de medidas excepcionais sobre a gestão, como se pode observar em alguns trechos do decreto:

Art. $1^{\circ}$ Fica decretado estado de calamidade financeira no âmbito da Administração Pública Estadual.

Art. $2^{\circ}$ Os Secretários de Estado e os Dirigentes máximos dos órgãos e das entidades da Administração Pública Estadual, sob a coordenação da Secretária da Casa Civil, ficam autorizadas a adotar as medidas excepcionais necessárias à racionalização de todos os serviços públicos, salvo aqueles considerados essenciais para que não sofram solução de continuidade, mediante a edição dos atos normativos competentes (Decreto 53.303 de 21 de novembro de 2016). 
Com este grave contexto, editou-se então a Lei Complementar $\mathrm{n}^{\circ} 156$ de 28 de dezembro de 2016, com os termos do novo acordo entre Rio Grande do Sul e o governo federal, em especial com a definição que as parcelas voltariam a ser pagas em janeiro de 2017, mas haveria uma ampliação do prazo de pagamento para até 2048, assim como a redução dos juros e a adoção de um novo indexador, com a condição de que os Estados desistissem de questionar a dívida junto ao Supremo Tribunal Federal. (MENDES, 2020)

Na sequência, foi editada a Lei Complementar $n^{\circ} 159$ de 19 de maio de 2017, que estabeleceu o chamado Regime de Recuperação Fiscal para Estados em profunda crise financeira, permitindo a contratação de novos financiamentos através de contrapartidas, a suspensão do pagamento da dívida por 3 anos, prorrogáveis por mais 3 anos, com a adoção de diversas medidas de austeridade com vistas a flexibilizar o texto do acordo e permitir que novos estados consigam ingressar neste programa de recuperação, a fim de sanear as finanças públicas e atingir o equilíbrio fiscal. (MENDES, 2020). O mesmo ajuste fiscal para tentar equacionar os gastos públicos foi seguindo pelo atual Governador do Estado, Eduardo Leite (2019-2022) e sua equipe, que também deram sequência a reformas estruturantes.

Apesar de todos estes movimentos, a crise da dívida pública do Estado do Rio Grande do Sul com a União (dívida interna) persiste até os dias de hoje. Em se tratando dos patamares atuais da dívida do Estado, segundo o último relatório da Dívida Pública Estadual, divulgado pela Secretaria Estadual da Fazenda - SEFAZ RS em 2020, com dados atualizados até dezembro de 2019, o Estado do Rio Grande do Sul finalizou o ano de 2019 com um passivo de $\mathrm{R} \$ 77,2$ bilhões, sendo deste montante, $\mathrm{R} \$ 68,6$ bilhões ( $88,8 \%$ do valor total) em dívida interna e R \$ 8,6 bilhões (11,2\% do valor total) em dívida externa (BUBLITZ, 2020).

A partir de dados extraídos do Relatório de Transparência Fiscal do Estado do Rio Grande do $\mathrm{Sul}^{6}$, publicação quadrimestral da Secretaria de Estado da Fazenda do Rio Grande do Sul - SEFAZ RS, pode-se perceber o seguinte:

\begin{abstract}
A Despesa de Pessoal (R\$ 30,5 bilhões) caiu 2,2\%, revertendo a trajetória de crescimento real observado há mais de dez anos. A queda é resultado do controle dessas despesas desde o início de 2019 (vedação de aumentos e redução de novas contratações), dos efeitos das Reformas Administrativa e Previdenciária, do fim do impacto dos reajustes salariais na segurança pública, implementados até 2018, e da redução nos gastos judiciais de pessoal (Precatórios e RPVs); [...] a Receita Total do Estado, já excluídos os repasses aos Municípios e ao FUNDEB, atingiu R $\$ 64,0$ bilhões no encerramento do exercício de 2020, correspondendo a um crescimento nominal de 6,8\% sobre 2019, superando a inflação acumulada em 12 meses medida pelo IPCA (4,52\%). No mesmo período, a Despesa Total Empenhada cresceu 2,0\%,
\end{abstract}


atingindo R \$ 64,6 bilhões, o que resultou num déficit orçamentário total de R \$ 597 milhões, uma melhoria significativa frente ao déficit orçamentário de R \$ 3,4 bilhões registrado em 2019. (GOVERNO DO ESTADO DO RIO GRANDE DO SUL, 2020, p. 7-9)

Sabe-se que no ano de 2020 o Estado, assim como todo o mundo, amargou uma enorme crise sanitária e econômica em decorrência da pandemia da Covid-19. O relatório descreve uma melhoria significativa frente ao déficit de 2019, mesmo contabilizando neste montante o valor de $\mathrm{R} \$ 3,5$ bilhões, relativo às despesas da dívida junto à União que não foram pagas ainda por força de liminar.

O Estado segue engajado na negociação com a União para adesão ao Regime de Recuperação Fiscal (RRF). Em janeiro de 2021, foi sancionada a Lei Complementar 178/2021, que traz aprimoramentos ao RRF, e cuja elaboração contou com a participação ativa do Estado. O RS, juntamente com outros estados, vem participando, desde o início de janeiro, a convite da Secretaria do Tesouro Nacional, da elaboração

\footnotetext{
${ }^{6}$ Sobre a questão da transparência na gestão pública, para maior aprofundamento ver: (SANTIN; TONIETO, 2007)

do decreto de regulamentação do RRF, cuja publicação está prevista para março. As etapas seguintes incluem a formalização do pedido de adesão e a elaboração do Plano de Recuperação Fiscal. (GOVERNO DO ESTADO DO RIO GRANDE DO SUL, 2020, p. 13)
}

Pode-se perceber que o Estado vive uma constante crise estrutural em seus gastos públicos, em especial nas despesas com pessoal e o peso dos inativos sobre a folha de pagamento (G1RS, 2017) ${ }^{7}$, provocando assim um descompasso significativo entre a receita e a despesa desde meados da década de 70. O governo de Eduardo Leite, seguindo a toada reformista da União, promoveu importantes medidas de austeridade contra o seu maior gargalo: as despesas com pessoal. Veja-se:

Com a aprovação da EC Estadual no 78/2020, promulgada em fevereiro, a tendência é de desaceleração do crescimento da folha de pagamentos nos próximos anos. A reforma administrativa extinguiu avanços temporais, adicionais e gratificações por tempo de serviço, assim como as promoções automáticas e a incorporação das funções na aposentadoria, preservando o direito adquirido sobre valores que já tinham sido incorporados aos pagamentos dos servidores públicos do Estado. Além dessas mudanças, que foram implementadas transversalmente nas categorias de servidores estaduais, o Governo Estadual aprovou a reforma dos Estatutos do Magistério e da Brigada Militar, que correspondem às categorias que concentram a maior parcela dos servidores. Dentro do conjunto das Despesas de Pessoal, embora a questão previdenciária mantenha-se como o elemento de maior peso no déficit do Estado, ocorreu uma reversão na trajetória de crescimento já em 2020, em decorrência das profundas alterações na previdência estadual realizadas pela $\mathrm{LC}^{\circ}{ }^{\circ} 15.429 / 2019$ e pela $\mathrm{EC}^{\circ}{ }^{\circ} 78 / 2020$ A reforma da previdência estadual representa a fonte mais importante de economia fiscal no longo prazo e a adequação do sistema previdenciário à rápida transição demográfica vivenciada no Estado é fator fundamental para a sustentabilidade fiscal. As alterações na previdência estadual, voltadas para reduzir o 
déficit atuarial e o déficit financeiro anual nas contas estaduais, incluíram desde a ampliação da base de incidência, à adoção de alíquotas progressivas e adoção das idades mínimas e tempos de contribuição instituídos para os servidores federais, correspondendo à reforma de regime próprio mais profunda realizada até o momento. Os efeitos já podem ser observados em 2020, que evidenciou melhora de 17,0\% no déficit previdenciário do Fundo Financeiro, que caiu de R \$12,4 bilhões (2019) para $\mathrm{R} \$ 10,3$ bilhões (2020). (GOVERNO DO ESTADO DO RIO GRANDE DO SUL, 2020, p. 11-12)

Entretanto, o grau de endividamento do Estado, que é histórico, continua em patamares bilionários. A partir dos dados extraídos do relatório estadual de transparência físcal para o ano de 2020,

\begin{abstract}
A Dívida Consolidada Líquida para fins do limite da LRF atingiu $\mathrm{R} \$ 93,3$ bilhões, incluindo basicamente os valores junto ao Governo Federal, Banco Mundial, BID, BNDES, Banco do Brasil e Caixa Econômica Federal, bem como Precatórios. Esse saldo apresentou um crescimento de 4,5\% sobre o ano de 2019, causado, principalmente, pelo não pagamento das prestações com a União ( $\mathrm{R} \$ 3,5$ bilhões no período) e pelo efeito da depreciação cambial sobre o estoque de dívida externa. Amparado em liminar, o pagamento das parcelas referentes ao serviço da dívida com a União está suspenso desde agosto de 2017. A Dívida Contratual atingiu R \$ 81,6
\end{abstract}

\footnotetext{
${ }^{7}$ Para maior aprofundamento sobre limites da Lei de Responsabilidade Fiscal com gastos de pessoal ver: (SANTIN; PEREIRA; CAMARGO, 2017)
}

bilhões ao final de 2020 , crescimento de $5,1 \%$, correspondente a acréscimo de $\mathrm{R} \$ 4$ bilhões. A segmentação por credor é apresentada na tabela abaixo, sendo R \$ 69,1 bilhões junto à União, $\mathrm{R} \$ 1,4$ bilhão junto a bancos públicos federais, $\mathrm{R} \$ 436$ milhões em parcelamentos com a Receita Federal e R \$ 10,7 bilhões junto a organismos internacionais. [...] O Estado segue negociando sua adesão ao Regime de Recuperação Fiscal (RRF) junto ao Governo Federal. Em 13 de janeiro de 2021, foi sancionada a Lei Complementar 178/2021, que traz aprimoramentos ao Regime de Recuperação Fiscal, e cuja elaboração contou com a participação ativa do RS para torná-la mais atrativa e, assim, auxiliar o Tesouro Estadual a quitar, no longo prazo, passivos acumulados no passado. O prazo do RRF foi alongado de seis para até dez anos (um ano para a conclusão da negociação com a União e até nove anos após a homologação). O novo formato prevê a retomada gradual do pagamento de parcelas da dívida com a União já no segundo ano de vigência, porém com prestações mais suaves, que crescem gradualmente a cada ano. Permite também incluir no conjunto de dívidas beneficiadas com a suspensão de pagamentos os financiamentos garantidos pela União (como os celebrados com o BNDES, BID e Banco Mundial). Com as novas regras, o RS poderá ainda financiar em 30 anos os saldos não pagos acumulados por conta da liminar (R\$ 11,1 bilhões), com encargos de adimplência, cujo pagamento inicia-se no segundo mês subsequente à adesão ao Regime. A definição das condições financeiras necessárias para a adesão, as medidas obrigatórias e as vedações também foram revistas no novo RRF, apresentando aderência ao ajuste fiscal gaúcho já em andamento. (GOVERNO DO ESTADO DO RIO GRANDE DO SUL, 2020, p. 43)

Diante do crônico cenário de crise vivenciado pelo Estado do Rio Grande do Sul, cabe agora discutir as consequências que este descompasso estrutural acaba por gerar nos setores econômicos do Estado, nos pagamentos e, sobretudo, na execução das políticas públicas em âmbito nível estadual. Políticas estas, que mexem com importantes áreas da atuação estatual, 
em especial, a área da infraestrutura e logística, da segurança pública, bem como dos direitos sociais como a saúde, gravemente impactada após a pandemia da Covid-19, em 2020.

\section{AS CONSEQUÊNCIAS DA CRISE PARA A EXECUÇÃO DAS POLÍTICAS PÚBLICAS NO ESTADO DO RIO GRANDE DO SUL}

Como se pode observar no tópico anterior, o Estado do Rio Grande do Sul desde meados da década de 70 vem vivenciando ano após ano, governo após governo, uma crônica crise estrutural em suas finanças. Crise esta, que nos últimos anos se aprofundou ainda mais em decorrência da instabilidade do cenário econômico, do padrão recessivo da economia brasileira, do descontrole dos gastos públicos e dos problemas estruturais que perseguem o Estado, como o descompasso entre receita e despesa e os problemas previdenciários no Regime Próprio de Previdência Social dos servidores públicos. Apesar dos esforços do atual governo em enquadrar o Estado no plano de Recuperação Fiscal do Governo Federal, na atualidade o sistema ainda é altamente deficitário, possuindo o título de Estado com o segundo maior déficit em números absolutos, atrás apenas do Estado de São Paulo. Porém, quando se vê o percentual do déficit por habitante, o Estado ocupa o primeiro lugar. (GAÚCHA ZH, 2016)

As consequências da baixa capacidade de investimento do Estado do Rio Grande do Sul são refletidas nas mais diferentes áreas, dentre elas a infraestrutura e logística das rodovias estaduais, bem como também no acesso asfáltico aos municípios. Segundo levantamento de GaúchaZH, dos 497 municípios do Rio Grande do Sul, 54 não possuem acesso asfáltico e sofrem com a capacidade de escoamento da produção agrícola, reflexos que são sentidos de forma direta no desenvolvimento econômico destes municípios e consequentemente no Estado. O levantamento ainda revela que "dos 17.466 quilômetros de malha rodoviária que serpenteia o Estado, 21,31\% ainda é de terra" (KERVALT, 2020) ou seja, para "interligar todos esses municípios por asfalto significa pavimentar ainda 778,48 quilômetros de rodovias" (KERVALT, 2020). Recursos que hoje o Estado não dispõe em caixa para realização.

Todavia, além da problemática do acesso asfáltico aos municípios, o Estado ainda carece de duplicação em algumas rodovias estaduais. Sendo o caso mais emblemático a duplicação da RS-118, uma importante rodovia que liga a capital Porto Alegre e cidades da região metropolitana ao litoral. A presente obra, iniciada em julho de 2006, é um dos reflexos mais memoráveis da crise das finanças públicas estaduais, que pelos escassos recursos para investimentos foi interrompida diversas vezes, passando assim por diversos governos e que 
atualmente no ano de 2020 está com 94\% da obra concluída. (JORNAL DO COMÉRCIO, 2020).

Além da infraestrutura e do desenvolvimento econômico, os reflexos da crise são sentidos de forma direta em uma área sensível aos direitos sociais, a saúde. Os sucessivos atrasos nos repasses de recursos por parte do Governo do Estado aos hospitais e clínicas municipais que executam algumas políticas públicas importantes para o Sistema Único de Saúde, é mais uma das facetas da crise, o que ocasionou nos últimos anos no fechamento de leitos clínicos, adiamento de cirurgias, atrasos salariais para trabalhadores da área da saúde e até mesmo fechamento de hospitais (GAÚCHA ZH, 2016). Com o atraso dos repasses, a execução de políticas públicas em importantes áreas que dependem das verbas de incentivo do Estado, como leitos psiquiátricos e de atenção a usuários de drogas, captação de órgãos e tecidos para transplantes, UTI neonatal e rede de apoio ao Serviço Móvel de Urgência (Samu), o Programa de Estratégia de Saúde da Família (PSF), o Primeira Infância Melhor (PIM) e a manutenção de Unidades de Pronto Atendimento (UPA), acabam sendo afetadas drasticamente.

E essa situação por certo foi agravada com a pandemia da Covid-19. Para se ter uma ideia, até novembro de 2018, o Estado do Rio Grande do Sul acumulava um passivo com Hospitais e Municípios na ordem de R \$ 655 milhões, sendo R \$ 155 milhões com Santas Casas e Hospitais filantrópicos e R\$ 500 milhões com municípios (BUBLITZ, 2018).

Importante salientar, que o passivo de $\mathrm{R} \$ 216$ milhões herdados pelo atual governo em 2019 foi quitado em 16 parcelas, tendo a última parcela paga em setembro do presente ano. E apesar dos crônicos problemas financeiros, o Estado do Rio Grande do Sul vem aplicando desde 2013 o percentual mínimo imposto pela Constituição Federal de 1988 para com os gastos em saúde (G1RS, 2020).

Ainda assim, após discorrer sobre as dificuldades históricas do Estado no quesito finanças públicas e suas implicações frente as políticas públicas, enfatiza-se também que a constante crise vivenciada pelo Rio Grande do Sul afeta de forma direta na elaboração de uma proposta de desenvolvimento econômico para o Estado. Todavia, a elaboração desta proposta passa por investimentos públicos e principalmente por investimentos do setor privado. No entanto, para superação da crise e criação de um quadro favorável ao investimento privado, é imprescindível a busca pelo equilíbrio das finanças públicas e a resolução dos problemas estruturais do Estado, que vêm se arrastando por décadas.

As medidas de ajuste fiscal que vem sendo implementadas desde 2015 foram de 
importante valia para o equacionamento do gasto público, ainda assim, soma-se a isso a busca pela adesão ao Regime de Recuperação Fiscal, por meio de um diálogo permanente com o Governo Federal, com vistas a iniciar um novo tempo na administração pública estadual que tenha por objetivo a construção de uma administração saudável, sustentável e que tenha como prioridade a eficiência e o resultado nas ações estatais. E nessa feita, construir um projeto claro de desenvolvimento econômico para o Estado que vise superar décadas de uma pauta de crise, sem dúvidas, passa pela modernização do setor público, novas parcerias com a sociedade civil e medidas de ajuste fiscal.

\section{CONSIDERAÇÕES FINAIS}

Após discorrer sobre a crise enfrentada pelo Setor Público no Brasil, não restam dúvidas das inúmeras consequências que a crise fiscal tem gerado para a busca da efetivação do desenvolvimento econômico, estrutural e social do estado, convertendo-se em um dos temas de grande relevância para o Direito Público na atualidade. Ao mesmo tempo, mostra-se um imenso desafio para os gestores em tempos de pandemia, recessão de econômica e queda aguda na arrecadação.

Diante do contexto de crise das finanças públicas do Estado do Rio Grande do Sul e suas implicações na execução das políticas públicas, conclui-se que a evolução desta crise com o passar do tempo trouxe ao estado um grave retrocesso na elaboração e execução de projetos e políticas públicas, nas mais diferentes áreas da administração estadual. Isso pode ser observado com a redução significativa dos investimentos estatais à medida em que a crise se aprofunda, o que torna um desafio e tanto para os diferentes governadores que passaram e ainda irão passar pelo Palácio Piratini.

Ainda assim, a crise da dívida do Estado que se arrasta desde meados da década de 70 é outro fator que agrava a situação fiscal, pois com o passar do tempo inúmeras foram as tentativas lançadas pelo Governo Estadual e Federal para o equacionamento desta dívida. Todavia, se forem somados o fator de descompasso estrutural entre a receita e a despesa, nenhuma medida até o momento foi capaz de amenizar a grave situação do Rio Grande do Sul.

Apesar de ter havido um certo "respiro" para o Estado com o Acordo da Dívida com a União proveniente da Lei 9.496/97, a qual federalizou a dívida do Estado e passou a ter o Governo Federal como principal credor, o problema do endividamento crônico continuou se arrastando e agravando nos últimos anos, chegando em 2015 a ter sucessivos atrasos nos 
pagamentos e os consequentes bloqueios das contas estaduais, medidas de contenção já previstas no acordo da federalização da dívida.

Diante deste quadro histórico, reforça-se a necessidade de medidas permanentes de equilíbrio financeiro, de modernização da máquina pública, de responsabilidade e de auxílio do Governo Federal, para assim construir um amplo pacto pela superação deste contexto de crise presente desde a década de 1970.

Finaliza-se o trabalho enfatizando a necessidade de se construir uma verdadeira agenda de desenvolvimento para o Estado, capaz de priorizar investimentos públicos e privados em infraestrutura e logística e qualificação dos serviços públicos. Mas para isso ocorrer, sem dúvida, será necessário se não superar, estabilizar a crise financeira estadual, que relegou o Estado do Rio Grande do Sul, antes o grande "celeiro da nação", em uma posição de subalternidade no pacto federativo brasileiro.

\section{REFERÊNCIAS BIBLIOGRÁFICAS}

ASSEMBLEIA LEGISLATIVA DO RIO GRANDE DO SUL. Relatório Final da Comissão Especial da Dívida Pública do Estado do Rio Grande do Sul. 2012. Disponível em: http://www.al.rs.gov.br/download/ComEspDivida_2012/RF_\%20Divida_2012.pdf. Acesso em 26 mar. 2021.

BARBOSA FILHO, Fernando de Holanda. A crise econômica de 2014/2017. Estudos Avançados, v. 31, n. 89, pp. 51-60, 2017. Disponível em: $<$ http://www.scielo.br/scielo.php?script=sci_arttext\&pid=S010340142017000100051\&lng=en\&nrm=iso>. Acesso em 25 mar. 2021. https://doi.org/10.1590/s0103-40142017.31890006.

BRASIL. Lei 7.614 de 14 de julho de 1987. Autoriza a realização, em caráter extraordinário, de operações de crédito à conta e risco do Tesouro Nacional, e dá outras providências. Disponível em: <http://www.planalto.gov.br/ccivil_03/LEIS/1980-1988/L7614.htm>Acesso em: 29 de março de 2021.

BRASIL. Lei 7.976 de 27 de dezembro de 1989. Dispõe sobre o refinanciamento pela União da dívida externa de responsabilidade dos Estados, do Distrito Federal e dos Municípios, inclusive suas entidades da Administração Indireta, e dá outras providências. Disponível em: <http://www.planalto.gov.br/CCivil_03/leis/L7976.htm>Acesso em: 29 de março de 2021.

BRASIL. Lei 9.496 de 11 de setembro de 1997. Estabelece critérios para a consolidação, a assunção e o refinanciamento, pela União, da dívida pública mobiliária e outras que especifica, de responsabilidade dos Estados e do Distrito Federal. Disponível em:

<http://www.planalto.gov.br/ccivil_03/leis/19496.htm>Acesso em: 29 de março de 2021.

BRASIL. Lei Complementar 101 de 04 de maio de 2000. Estabelece normas de finanças 
públicas voltadas para a responsabilidade na gestão fiscal e dá outras providências. Disponível em: <http://www.planalto.gov.br/ccivil_03/leis/lcp/lcp101.htm>Acesso em 29 de março de 2021.

BRASIL. Lei Complementar 148 de 25 de novembro de 2014. Altera a Lei Complementar $\mathrm{n}^{\mathrm{o}}$ 101, de 4 de maio de 2000, que estabelece normas de finanças públicas voltadas para a responsabilidade na gestão fiscal; dispõe sobre critérios de indexação dos contratos de refinanciamento da dívida celebrados entre a União, Estados, o Distrito Federal e Municípios; e dá outras providências. Disponível em: <http://www.planalto.gov.br/ccivil_03/leis/lcp/lcp148.htm>Acesso em 29 de março de 2021.

BRASIL. Lei Complementar 156 de 28 de dezembro de 2016. Estabelece o Plano de Auxílio aos Estados e ao Distrito Federal e medidas de estímulo ao reequilíbrio fiscal; e altera a Lei Complementar $\mathrm{n}^{\mathrm{0}}$ 148, de 25 de novembro de 2014, a Lei no 9.496, de 11 de setembro de 1997, a Medida Provisória $\mathrm{n}^{-}$2.192-70, de 24 de agosto de 2001, a Lei $\mathrm{n}^{\mathrm{o}}$ 8.727, de 5 de novembro de 1993, e a Lei Complementar $\mathrm{n}^{\mathrm{o}}$ 101, de 4 de maio de 2000. Disponível em: <http://www.planalto.gov.br/ccivil_03/leis/lcp/Lcp156.htm> Acesso em: 29 de março de 2021.

BRASIL. Lei Complementar 159 de 19 de maio de 2017. Institui o Regime de Recuperação Fiscal dos Estados e do Distrito Federal e altera as Leis Complementares n⿳⼈ㅜ 101, de 4 de maio de 2000, e n⿳⺈ 156, de 28 de dezembro de 2016.Disponível em:<

http://www.planalto.gov.br/ccivil_03/leis/lcp/lcp159.htm>Acesso em 29 de março de 2021.

BUBLITZ, Juliana. Com agravamento da crise, Governo do RS soma R\$ 655 milhões ematrasos na saúde. GZH, 11 de novembro de 2018. Disponível em: <

https://gauchazh.clicrbs.com.br/politica/noticia/2018/11/com-agravamento-da-crise-governodo-rs-soma-r-655-milhoes-em-atrasos-na-saude-cjodfvcsw0d2k01pi0db5b3gd.html> Acesso em 29 de março de 2021.

BUBLITZ, Juliana. Com parcelas suspensas há três anos, dívida do RS segue crescendo e voltaa bater recorde. GZH, 20 de julho de 2020. Disponível em:

$<$ https://gauchazh.clicrbs.com.br/economia/noticia/2020/07/com-parcelas-suspensas-ha-tresanos-divida-do-rs-segue-crescendo-e-volta-a-bater-recorde-

ckcusdce3002u013ghinn520q.html> Acesso em 29 de março de 2021.

BUBLITZ, Juliana. Saiba como surgiu e se formou a dívida do Estado do RS. GZH, 01 de julhode 2016. Disponível em:

<https://gauchazh.clicrbs.com.br/politica/noticia/2016/07/saiba-como-surgiu-e-se-formou-adivida-do-estado-do-rs- cj80qaofx00zj01 mjnzr64uxo.html> Acesso em 29 de março de 2021.

CÂMARA DOS DEPUTADOS. Entenda o que é receita corrente líquida, 13 de julho de 2004. Disponível em: <https://www.camara.leg.br/noticias/51956-entenda-o-que-e-receitacorrente-

liquida/\#: :text=Receita\%20corrente\%201\%C3\%ADquida\%20\%C3\%A9\%20o,os\%20valores \%20das\%20transfer\%C3\%AAncias\%20constitucionais.> Acesso em 29 de março de 2021.

DAMAS, Roberto Dumas. Crises Econômicas Internacionais. São Paulo: Saraiva, 2017. 
FORNI, João José. Gestão de crises e comunicação: o que os gestores e profissionais decomunicação precisam saber para enfrentar crises corporativas. 3. ed. São Paulo: Atlas, 2019 .

G1RS. Despesa com inativos toma mais da metade da folha de pagamento do governo do RS. 07 de abril de 2017. Disponível em: <https://g1.globo.com/rs/rio-grande-dosul/noticia/despesa-com-inativos-toma-mais-da-metade-da-folha-de-pagamento-do-governodo-rs.ghtml> Acesso em 29 de março de 2021.

G1RS. Governo do RS quita parcelamento na área da saúde com hospitais e prefeituras, 24 de setembro de 2020. Disponível em: <https://g1.globo.com/rs/rio-grande-dosul/noticia/2020/09/24/governo-do-rs-quita-parcelamento-na-area-da-saude-com-hospitais-eprefeituras.ghtml> Acesso em: 22 de dezembro de 2020.

GAÚCHA ZH. Saiba como surgiu e se formou a dívida do Estado do RS. 01 jul. 2016. Disponível em: https://gauchazh.clicrbs.com.br/politica/noticia/2016/07/saiba-como-surgiu-ese-formou-a-divida-do-estado-do-rs-cj80qaofx00zj01mjnzr64uxo.html. Acesso em 29 de março de 2021.

GOVERNO DO ESTADO DO RIO GRANDE DO SUL. RTF-Relatório de Transparência Fiscal: data base dezembro de 2020 . 4.ed. Porto Alegre: Secretaria de Estado da Fazenda do Rio Grande do Sul, 2020. Disponível em: https://estado.rs.gov.br/upload/arquivos/relatorio-rtfdezembro-20.pdf. Acesso em 29 mar. 2021.

GUIMARÃES, Raymundo Ferreira. Agravamento da crise financeira do Estado do Rio Grandedo Sul no período de 1979 a 1985 e suas consequências atuais. Indicadores Econômicos FEE,Porto Alegre, v. 34, n. 4, p. 123-128, mar. 2007. Disponível em: https://revistas.dee.spgg.rs.gov.br/index.php/indicadores/article/view/1530/1900. Acesso em 29 mar. 2021.

JORNAL DO COMÉRCIO. Duplicação da RS-118 deve ficar pronta fim do ano. 23 de setembro de 2020. Disponível em: <https://www.jornaldocomercio.com/_conteudo/especiais/anuario_de_investimentos_2020/20 20/09/757921-duplicacao-da-rs-118-deve-ficar-pronta-fim-do-ano.html> Acesso em: 29 de março de 2021.

KERVALT, Marcelo. No RS, 54 municípios ainda não tem acesso asfáltico e sofrem com poeira, buracos e dificuldades econômicas. 21 de fevereiro de 2020. Disponível em: < https://gauchazh.clicrbs.com.br/geral/noticia/2020/02/no-rs-54-municipios-ainda-nao-temacesso-asfaltico-e-sofrem-com-poeira-buracos-e-dificuldades-economicasck6wm0wqt017401qdr1onait8.html> Acesso em 29 de março de 2021.

MARQUES JÚNIOR, Liderau dos Santos. A crise financeira do RS e seus componentes. Cartade Conjuntura FEE. Ano 24, n. 10, 2015. Disponível em: http://carta.fee.tche.br/article/a- crise-financeira-do-rs-e-seus-componentes/. Acesso em 25 mar. 2021.

MARQUES, Mauro Luiz Barbosa. A simbólica presença das sinetas nos embates entre trabalhadores em educação e governos (Rio Grande do Sul, 1985-1991). Revista Labor, v. 2, 
n. 18, ed. especial, p. 135-149, nov. 2017. Disponível em:

http://repositorio.ufc.br/bitstream/riufc/38308/1/2017_art_mlbmarques.pdf. Acesso em 26 mar. 2021.

MENDES, Guilherme. Câmara aprova socorro a estados e municípios e refinanciamento dedívidas. UOL Congresso em foco, 15 de dezembro de 2020. Disponível

em:<https://congressoemfoco.uol.com.br/legislativo/camara-socorro-a-estados-emunicipios/> Acesso em 29 de março de 2021.

RIO GRANDE DO SUL. Decreto 53.303 de 21 de novembro de 2016. Disponível em: $<$ https://leisestaduais.com.br/rs/decreto-n-53303-2016-rio-grande-do-sul-estado-decalamidade-financeira-no-ambito-da-administracao-publica-estadual>Acesso em 29 de março de 2021.

SANTIN, Janaína Rigo; BITENCOURT, Jean Carlos Menegaz. Pacto federativo e autonomia legislativa municipal. História: Debates e Tendências, vol. 15, n. 1, 2015, pp.101-113. Redalyc, https://www.redalyc.org/articulo.oa?id=552456385007.

SANTIN, Janaína Rigo; TONIÊTO, Tiago. O Princípio da Transparência e a Participação Popular na Administração Pública. Revista Brasileira de Direito Municipal, Belo Horizonte, v. $8, \quad$ n. $26, \quad$ p. 21-29, out./dez. 2007. Disponível em: <http://dspace.almg.gov.br/xmlui/bitstream/item/5653/PDIexibepdf.pdf?sequence=1>. Acesso em: 29 abr. 2013.

SANTIN, Janaína Rigo; PEREIRA, André da Silva; CAMARGO, Evandro José Bilycz de. Administração pública municipal e lei de responsabilidade fiscal: gastos e receitas públicas. Revista de Direito Brasileira, v. 17, n. 7, p. 108-124, 2017. Disponível em: https://indexlaw.org/index.php/rdb/article/view/3145. Acesso em 29 mar. 2021.

SILVA, Luciana Mettedi e. O exame do equilíbrio financeiro da dívida renegociada sob o ampara do Lei $n^{\circ}$ 9.496/97 e do programa de incentivo à redução da presença do setor público estadual na atividade financeira bancária - PROES. Tesouro do Estado do Rio Grande do Sul, 2014. Disponível em: https://tesouro.fazenda.rs.gov.br/upload/1601407495_20171002145142exame_do_equilibrio_ financeiro_da_divida_renegociada.pdf> Acesso em 29 de março de 2021.

STEPHANES, Reinhold. A incompreensão do caixa único. Gazeta do Povo, 30 de julho de 2013. Disponível em: <https://www.gazetadopovo.com.br/opiniao/artigos/a-incompreensaodo-caixa-unico-btxfvb9j6f0e8ncjsu8mlc5e6/>Acesso em 29 de março de 2021. 